Research Article

\title{
The Absorption, Distribution, and Excretion of 18 Elements of Tibetan Medicine Qishiwei Zhenzhu Pills in Rats with Cerebral Ischemia
}

\author{
Yinglian Song, ${ }^{1}$ Ke Fu, ${ }^{1}$ Dewei Zhang, ${ }^{2}$ Min Xu, ${ }^{1}$ Ruixia Wu, ${ }^{1}$ Xueqing Xiong, ${ }^{2}$ Xianwu Liu, \\ Lei Wu, ${ }^{1}$ Ya Guo, ${ }^{2}$ You Zhou, ${ }^{1}$ Xiaoli Li, ${ }^{1}$ and Zhang Wang $\mathbb{D}^{3}$ \\ ${ }^{1}$ College of Pharmacy, Chengdu University of Traditional Chinese Medicine, Chengdu 611137, China \\ ${ }^{2}$ Wanzhou Institute for Drug and Food Control, Chongqing 404000, China \\ ${ }^{3}$ College of Ethnomedicine, Chengdu University of Traditional Chinese Medicine, Chengdu, 611137, China
}

Correspondence should be addressed to Zhang Wang; wangzhangcqcd@cdutcm.edu.cn

Received 4 October 2021; Revised 12 December 2021; Accepted 13 December 2021; Published 28 December 2021

Academic Editor: Lixin Wei

Copyright ( 2021 Yinglian Song et al. This is an open access article distributed under the Creative Commons Attribution License, which permits unrestricted use, distribution, and reproduction in any medium, provided the original work is properly cited.

\begin{abstract}
The aim of this study is to determine 18 elements in Tibetan medicine Qishiwei Zhenzhu pills (QSW) and their absorption, distribution, and excretion in rats with cerebral ischemia. Microwave digestion and inductively coupled plasma mass spectrometry (ICP-MS) were used to determine 18 elements of QSW in simulated gastrointestinal (GI) juice. Rats were given QSW $(66.68 \mathrm{mg} / \mathrm{kg})$ followed by middle cerebral artery occlusion (MCAO). Sham rats received saline and were not subjected to MCAO. ICP-MS was applied to determine the content of 18 elements in hepatic venous blood, abdominal aortic blood, brain, liver, kidney, hair, urine, and feces $24 \mathrm{~h}$ after MCAO. In vitro results showed that the extraction rate of $\mathrm{Mn}, \mathrm{Cu}, \mathrm{Sr}, \mathrm{Pb}, \mathrm{Au}$, and $\mathrm{Hg}$ of QSW in gastric juice $(1 \mathrm{~h})$ was higher than that in water, and the contents of $\mathrm{Cu}, \mathrm{Au}, \mathrm{Sr}$, and As were higher in intestinal juice $(4 \mathrm{~h})$ than in water. In vivo results showed that the contents of elements in the blood were quite low, and QSW increased $\mathrm{Ni}, \mathrm{Cr}, \mathrm{Sr}, \mathrm{Co}$, and $\mathrm{V}$ in artery blood and decreased V in venous blood. Elements in the tissues were also low, and QSW increased brain Li but decreased Cr and Cd; QSW increased kidney Ag and Cs and liver Mn but decreased liver Ni. QSW increased urinary excretion of $\mathrm{Li}, \mathrm{Sr}, \mathrm{Hg}$, Cs, and V; QSW increased $\mathrm{Hg}$ content in hair but decreased Ni. Stool is the main excretion pathway of the elements in QSW, with $\mathrm{Ba}, \mathrm{Mn}, \mathrm{Sr}, \mathrm{Cd}, \mathrm{V}, \mathrm{Cu}, \mathrm{Cs}, \mathrm{Li}, \mathrm{Pb}, \mathrm{Ag}, \mathrm{Hg}, \mathrm{Cr}, \mathrm{As}$, and Co the highest. In summary, this study examined the distribution of 18 elements in QSW-treated MCAO rats. The accumulation of these elements in blood and tissues was extremely low, and the majority was excreted in feces within $24 \mathrm{~h}$, highlighting the importance of the gut-microbiota-brain axis in QSW-mediated brain protection.
\end{abstract}

\section{Introduction}

Cerebral ischemia is the commonest type of cerebral infarction [1]. On the basis of vascular wall lesions caused by cerebral atherosclerosis, vascular stenosis, occlusion, or thrombosis may result in ischemia and hypoxic necrosis of local brain tissues due to interruption of the blood supply, which result in corresponding symptoms and signs in the nervous system [2]. Cerebral ischemia is equivalent to ischemic stroke in traditional Chinese medicine, "Baimai" disease in Tibetan medicine, and "Sa" disease in Mongolian medicine. The usual symptoms of "Baimai" disease are skewed mouth and eyes, numbness in limbs, rigidity, angular arch reflex, paralysis, hemiplegia, unconsciousness, and head tremors [3].

Qishiwei Zhenzhu pills (QSW), of which the Tibetan name is, are also known as Ranna Sangpei and was first recorded in the great classical work of Tibetan medicine $S i$ $B u$ Yi Dian. QSW have the functions of tranquilizing the mind, activating meridians and collaterals, and harmonizing qi and blood. They are mainly used to treat "Baimai" disease, "Longxue" disorder, stroke, paralysis, hemiplegia, epilepsy, 
cerebral hemorrhage, and other diseases [4]. According to the published literature, there should be 32 kinds of plant medicine, 8 kinds of animal medicine, more than 20 kinds of mineral and gem medicine, and a mineral mixture (Zuotai) in QSW. QSW are a confidential prescription, only the names of some medicines are disclosed, and the specific prescription proportion is unknown. Only 12 plant medicines, 8 animal medicines, 8 mineral and gemstone medicines, 4 metal medicines, and Zuotai are known and are listed in Supplementary Table 1 [5]. QSW consist of more than 10 metallic elements, such as gold, silver, and copper, more than 20 minerals and gemstones, such as sapphire and agate, and a mineral mixture Zuotai [6]. In particular, in accordance with the theories of Tibetan medicine, Zuotai is the main ingredient of many important Tibetan medicinal preparations. Zuotai is obtained from mercury and other minerals by a complex processing procedure, and hence QSW contain a large amount of mercury. The high mercury content in QSW results in serious health problems [7-9]. Therefore, the determination of the contents of mercury and other mineral components in QSW is very important for safety in clinical use.

The choice of detection method is important for the determination of trace elements, and a variety of different methods are used to detect elements. For example, Yang et al. [10] used synchrotron radiation X-ray fluorescence (SR-XRF) technology to quantify and semiquantify nine and fifteen elements in Tibetan herbal medicines and Tibetan medicine preparations, respectively. Flame atomic absorption (FAAS) with wet digestion method has also been used to quantitatively analyze various trace elements in Tibetan medicine Nan Hanshuishi [11]. In addition, the total mercury in the Tibetan medicine Dangzuo and the free mercury in the artificial gastric juice are also measured using the gold amalgam enrichment-atomic fluorescence (GAEAFS) method [12]. Among a variety of detection methods, compared with traditional inorganic analysis technology, ICP-MS technology has the advantages such as lower detection limit, wider dynamic linear range, less interference, higher analysis precision, and analysis speed, and it can provide accurate isotope information and has a wide range of applications [13]. In medicine, it can be applied to the analysis of hair, blood samples, urine samples, biological tissues, biological mechanism research of proteins, enzymes, etc., drug quality control, etc. [14]. This research uses ICPMS technology for experiment; the results will provide new ideas for the establishment of determination methods as well as the quality control and clinical rational application of QSW in the future [15].

As for the determination of trace elements in QSW, the following studies have been conducted: Suo et al. used inductively coupled plasma-atomic emission spectrometry (ICP-AES) to analyze and test more than 20 trace element components of QSW [16]. Li et al. used ICP-AES to determine the contents of 9 trace elements $(\mathrm{Cu}, \mathrm{Fe}, \mathrm{Co}, \mathrm{Mn}, \mathrm{V}$, $\mathrm{Zn}, \mathrm{Mg}, \mathrm{P}$, and $\mathrm{K}$ ) in QSW and provided a theoretical basis for explaining their clinical effects on the basis of synergistic and antagonistic elements [17]. Li and Suo analyzed the long-term accumulation and toxic effects of trace elements present in QSW in animal tissues and organs. The results showed that most of the trace elements present in QSW did not accumulate in the heart, liver, kidneys, or other tissues and organs. Excessive amounts of heavy metals such as arsenic and cadmium were ingested after the administration of QSW and were mainly excreted through feces and urine [18]. Du et al. quantitatively analyzed the contents and distribution of toxic heavy metals ( $\mathrm{As}, \mathrm{Hg}$, and $\mathrm{Pb}$ ) in QSW on the basis of the findings of Li et al. [19]; but, at present, there have been no studies of the accumulation of trace elements in the body during the treatment of cerebral ischemia with QSW. In this study, we established a new, sensitive, selective, and accurate method for simultaneous quantitative analysis of the contents in the simulated GI juice and water of 18 elements in the QSW and their absorption, distribution, and excretion in rats with cerebral ischemia. By comparing the contents in the simulated GI juice and water of each element and their changes in the blood, distribution in the brain, liver, and kidney tissues, and excretion in hair, urine, and feces, the pharmacodynamic medicinal substance basis and toxicity of the QSW and its metabolism in the body can be found.

We have shown that QSW are effective in the treatment of cerebral ischemia injury [20]. The disposition of 18 elements during the treatment of MCAO by QSW could add our understanding of the protection mechanisms of QSW against cerebral ischemia injury. The results clearly demonstrated that $24 \mathrm{~h}$ after QSW administration to MCAO rats, these elements' accumulation in the blood and tissues were extremely low, and the amount found in feces were extremely high, implying these elements in the GI tract could modulate gut microbiota [21] to produce neuroprotection through the gut-microbiota-brain axis.

\section{Materials and Methods}

2.1. Drugs. QSW (batch number: 17103A, Guoyao Zhunzi: Z54020062) was purchased from Tibet Ganlu Tibetan Medicine Co., Ltd.

2.2. Reagents. Rh (internal standard stock solution [ISS]), In (ISS), Re (ISS), Bi (ISS), Li (standard solution [SS]), Be (SS), Sc (SS), V (SS), Cr (SS), Mn (SS), Co (SS), Ni (SS), Cu (SS), As (SS), $\mathrm{Sr}$ (SS), Ag (SS), Cd (SS), Cs (SS), Ba (SS), Pb (SS), $\mathrm{Au}(\mathrm{SS})$, and $\mathrm{Hg}$ (SS) all 22 reagents were produced by the National Nonferrous Metals and Electronic Materials Analysis and Testing Center. Pepsin and pancreatin were manufactured by Xinxiangsheng Biopharmaceutical Co., Ltd.

2.3. Instruments and Working Parameters. An inductively coupled plasma mass spectrometer (ICP-MS) (mode: ICAPQ Series; Thermo Fisher Scientific, USA) was used with the following parameters: RF power $1.3 \mathrm{~kW}$, carrier gas flow rate $1.14 \mathrm{~L} / \mathrm{min}$, sampling depth $6.8 \mathrm{~mm}$, rectangular tube horizontal position $0.6 \mathrm{~mm}$, auxiliary gas flow rate $0.9 \mathrm{~L} / \mathrm{min}$, spray chamber flow rate $0.98 \mathrm{~L} / \mathrm{min}$, and spray chamber pressure $2.85 \times 105 \mathrm{~Pa}$. 
A microwave digestion apparatus (model: Milestone ETHOS A; Huashengda Instrument Equipment Co., Ltd.) was employed with the following parameters: (1) increase the temperature from room temperature to $120^{\circ} \mathrm{C}$ within $15 \mathrm{~min}$ and maintain for $5 \mathrm{~min}(1600 \mathrm{~W})$; (2) increase the temperature to $150^{\circ} \mathrm{C}$ within $7 \mathrm{~min}$ and maintain for another $7 \mathrm{~min}(1600 \mathrm{~W})$; and (3) within $7 \mathrm{~min}$, increase the temperature to $190^{\circ} \mathrm{C}$ and maintain for $15 \mathrm{~min}(1600 \mathrm{~W})$.

The following instruments were also used: an electronic analytical balance (model: XP204; Mettler-Toledo) and a constant temperature oscillator (model: SHZ-82; Guowang Instrument Manufacturing Co., Ltd.).

2.4. Preparation of Standard Solution. Gold working solutions with a mass concentration of $10 \mu \mathrm{g} / \mathrm{mL}$ were formulated (The Hg element easily produces memory effect as well as adsorption effect.). Precision stock solutions containing 18 tested metal elements, including $\mathrm{Li}, \mathrm{Be}, \mathrm{Sc}, \mathrm{V}, \mathrm{Cr}, \mathrm{Mn}, \mathrm{Co}$, $\mathrm{Ni}, \mathrm{Cu}, \mathrm{As}, \mathrm{Sr}, \mathrm{Ag}, \mathrm{Cd}, \mathrm{Cs}, \mathrm{Ba}, \mathrm{Pb}, \mathrm{Au}$, and $\mathrm{Hg}$, were used at appropriate amounts and diluted clinically with $10 \% \mathrm{HNO}_{3}$ to form mixed standard solutions with serial mass concentrations of each element: $\mathrm{Li}, \mathrm{Be}, \mathrm{Sc}, \mathrm{V}, \mathrm{Co}, \mathrm{Cd}, \mathrm{Cs}(0,0.5$, 2.0, 10, 25, $50 \mu \mathrm{g} / \mathrm{L})$; $\mathrm{Cr}, \mathrm{Mn}, \mathrm{Ni}, \mathrm{Cu}, \mathrm{As}, \mathrm{Sr}, \mathrm{Ag}, \mathrm{Ba}, \mathrm{Au}, \mathrm{Pb}(0$, $0.5,2.0,10,25,50) \times 10^{3} \mu \mathrm{g} / \mathrm{L} ; \mathrm{Hg}(0,0.2,0.5,1.0,1.5,2.0) \times$ $10^{2} \mu \mathrm{g} / \mathrm{L}$; the standard solutions of mercury were configured individually; and the other 17 elements were configured into mixed standard solutions. Precision stock solutions of internal standards containing $\mathrm{Rh}, \mathrm{Re}, \mathrm{In}$, and Bi diluted with $10 \% \mathrm{HNO}_{3}$ to a mixed internal standard solution at a concentration of $10 \mu \mathrm{g} / \mathrm{mL}$ and used.

2.5. Preparation of Test Samples of QSW. The QSW were wrapped with filter paper and crushed (not with a mortar to prevent the introduction of heavy metals). Exactly $0.0500 \mathrm{~g}$ of the sample was poured slowly into a polytetrafluoroethylene (PTEF) digestion tank, which was soaked in $\mathrm{HNO}_{3}$ overnight, washed, and dried. Afterward, $10 \mathrm{~mL}$ of $\mathrm{HNO}_{3}$ and $2 \mathrm{~mL}$ of $\mathrm{H}_{2} \mathrm{O}_{2}$ (both of premium grade) were added, shaken slowly, fixed, placed under the microwave heating program, and digested for $60 \mathrm{~min}$. After the digestion was completed, the microwave digestion apparatus was turned off and cooled for a while. The digestion tank was removed and cooled to room temperature. The test solution was transferred to a $50 \mathrm{~mL}$ volumetric flask and washed three to four times. A constant volume was achieved. Given that $\mathrm{Hg}$ is easy to be adsorbed, $0.1 \mathrm{~mL}$ of the sample was placed in a $50 \mathrm{~mL}$ volumetric flask and added with gold standard solution to stabilize for testing (equivalent to 500-fold dilution).

2.6. Sample Preparation of QSW after the Digestion of Simulated GI Juice. Artificial GI juice was prepared in accordance with the Pharmacopoeia of the People's Republic of China (2015 edition, Vol. IV) [22]. For the preparation of artificial gastric juice, $16.4 \mathrm{~mL}$ of diluted hydrochloric acid was added with $800 \mathrm{~mL}$ of water and $10 \mathrm{~g}$ of pepsin, shaken well, and diluted to $1000 \mathrm{~mL}$ with water. For the preparation of artificial intestinal juice, phosphate buffer (containing pancreatin) and 6-8g of potassium dihydrogen phosphate were dissolved in $500 \mathrm{~mL}$ of water, and the $\mathrm{pH}$ was adjusted to 6.8 with $0.1 \mathrm{~mol} / \mathrm{L}$ sodium hydroxide solution. In addition, $10 \mathrm{~g}$ of pancreatin was dissolved in an appropriate amount of water. The two liquids were then mixed, added with water, and diluted to $1000 \mathrm{~mL}$.

Simulated GI juice digestion and water samples were prepared using the method of Jin's research group [23]: $0.5000 \mathrm{~g}$ of finely ground QSW (approximately equivalent to the amount taken by a patient with mild to moderate diseases) was placed in a $200 \mathrm{~mL}$ conical flask with $100 \mathrm{~mL}$ of artificial gastric juice. The solution was vortexed at $37^{\circ} \mathrm{C}$ for $1 \mathrm{~h}$ and filtered, and the residual liquid was washed three times with artificial gastric juice. The filtrate was diluted with water to $200 \mathrm{~mL}$ to obtain an extract of artificial gastric juice. Another portion of the same sample powder was placed in a $200 \mathrm{~mL}$ conical flask filled with $100 \mathrm{~mL}$ of artificial intestinal juice, vortexed at $37^{\circ} \mathrm{C}$ for $4 \mathrm{~h}$, and filtered. The residue was washed three times with artificial intestinal juice, and the filtrate was diluted with water to $200 \mathrm{~mL}$ to obtain an extract of artificial intestinal juice. Another part of the same sample powder was placed in a $200 \mathrm{~mL}$ conical flask with $100 \mathrm{~mL}$ of water, and then two copies were made and vortexed at $37^{\circ} \mathrm{C}$ for $1 \mathrm{~h}$ and $4 \mathrm{~h}$, respectively, filtered, and rinsed with clean water three times. The filtrate was diluted to $200 \mathrm{~mL}$ with water to obtain the water extract. Approximately $1 \mathrm{~mL}$ was obtained for each of these four extracts, placed into the PTEF digestion tank, and added $4 \mathrm{~mL}$ of $\mathrm{HNO}_{3}$ (premium grade). The remaining steps were similar to "Preparation of Test Samples of QSW" to prepare the test solution for testing.

2.7. Experimental Animals. Twelve male SD rats of SPF grade weighing 250-280 g were purchased from Chengdu Dashuo Experimental Animal Co., Ltd. (license number: SCXK [Sichuan] 2015-030, experimental animal quality certificate number: No. 51203500008744). The experiment was conducted in the National Medicine Resource Evaluation Laboratory of the Chengdu University of Traditional Chinese Medicine (the third-level scientific research laboratory of the State Administration of Traditional Chinese Medicine, NO.TCM-2009-320).

2.8. Animal Grouping and Test Drug Dosage. All male SD rats were divided into the following two large groups, each group with 6 animals: Sham operation group (abbreviated as Sham) and Qishiwei Zhenzhu pills group (abbreviated as QSW + MCAO) $(66.68 \mathrm{mg} / \mathrm{kg})[24,25]$. Based on the group, the rats were administered saline or QSW once through intragastric administration, and the administration volume was $10 \mathrm{~mL} / \mathrm{kg}$. The dosage of $66.68 \mathrm{mg} / \mathrm{kg}$ QSW is 4 times the daily dose for clinical adults, which is the optimal dose [26, 27].

2.9. Preparation of the MCAO Model. Performing animal modeling immediately after intragastric administration, refer to the predecessor model preparation method [26-29], 
separate the right common carotid artery (CCA), external carotid artery (ECA), and internal carotid artery (ICA) and ligate the ECA. Separate the pterygopalatine artery inward along the ICA and ligate at the bifurcation. Cut an incision between the distal and proximal ends of the ECA, insert the tie wire into the ICA about $20 \mathrm{~mm}$, and suture the wound and sterilize it. The animal was kept warm until awoke after modeling. The middle cerebral artery was occluded for 2 hours and then reperfused. In the Sham group, only the wound was sutured and a model was not made.

2.10. Collection and Determination of Animal Samples. At $24 \mathrm{~h}$ after intragastric administration of saline in the Sham group and after successful modeling for $24 \mathrm{~h}$ in the QSW + MCAO group, 20\% urethane solution was injected intraperitoneally $(0.6 \mathrm{~mL} / 100 \mathrm{~g})$ to anesthetize the rats, and then the rats in each group were treated with heparin sodium anticoagulation tube to collect blood from the hepatic portal vein and abdominal aorta. After taking blood from the hepatic vein and abdominal aorta, the liver, brain, kidney, as well as feces, urine, and hair were quickly collected, and then the rats were killed with cervical dislocation. When taking urine, gently squeeze the abdomen of the rat's bladder to speed up the collection of urine. Abdominal aortic blood, hepatic portal vein blood, and urine samples were measured to $0.50 \mathrm{~mL}$ using a pipette. The feces were obtained from the colon, and the back hairs of rats were collected. The feces and hair samples were weighed at $0.5000 \mathrm{~g}$. And the brain, liver, and kidney were taken, weighed $0.5000 \mathrm{~g}$, and then were homogenized. Transfer each of the above samples into the PTEF digestion tank, and add $8 \mathrm{~mL} \mathrm{HNO}_{3}$ (premium grade), same as "Preparation of Test Samples of QSW"; finally, transfer the digested test solution to a $25 \mathrm{~mL}$ volumetric flask to constant volume to be tested.

2.11. Statistical Analysis. SPSS 21.0 software was used for data analysis, and the data were expressed as mean \pm SD. The independent sample $t$-test was performed for the comparison between two groups. When the test result is $p<0.05$, the difference between groups is considered to be significant.

\section{Results}

\subsection{In Vitro Quantitative Analysis of Minerals and Heavy Metals in QSW by ICP-MS}

3.1.1. Methodological Investigation. Referring to the preparation of standard curves by subject group of Guo et al. [30], the multiple mixed standard solution under "Preparation of Standard Solution" was injected into the instrument at the same time as the internal standard solution, and the determinations were performed sequentially; taking the average measurement value of 3 readings measured for each mass concentration as the ordinate $(y)$ and the mass concentration of the standard solution corresponding elements as the abscissa $(x)$, the standard curve was plotted; then linear regression was performed to obtain the regression equations of 18 metal elements, and the results are shown in
Supplementary Table 2. The results showed that each element had a good linear relationship in the corresponding mass concentration range. The mixed standard solution was taken for six consecutive injections, the contents of 18 minerals and heavy metals were determined, and the RSD value of the response value of each element was calculated; see Supplementary Table 2 for details. The measurement precision of the 18 elements is good and meets the analysis requirements.

Referring to the repeatability experiment of Guo Hong Li's research group [30], and using the same way, 6 sample solutions were prepared in parallel, and the sample solutions and the internal standard solutions were injected into the instrument at the same time; then sequential determination was performed, and the RSD value of each element is shown in Supplementary Table 2. The RSD values of the 18 elements were all less than 5\%, indicating good repeatability. In addition, accurately weighed 6 samples (QSW), each $0.0250 \mathrm{~g}$, referring to "Preparation of Test Samples of QSW" to prepare sample solutions and internal standard solutions were prepared according to "Preparation of Standard Solution," then the sample solutions and internal standard solutions were injected into the instrument at the same time, and the recovery rates of 18 elements were calculated. The results are shown in Supplementary Table 2. The average sample recovery rate of 18 elements is $95.10 \%-111.13 \%$ (RSD, 2.13\%-4.24\%).

Referring to "Preparation of Test Samples of QSW," the blank solution was prepared by the same method, injected into the instrument, and measured 11 times continuously, and the detection limit of each element was obtained. See Supplementary Table 2 for details.

3.1.2. Content of Minerals and Heavy Metal Elements in QSW. After detection by ICP-MS, the contents of 18 elements in QSW are obtained: Li $2.893 \mu \mathrm{g} / \mathrm{kg}$, Be $1.504 \mu \mathrm{g} / \mathrm{kg}$, Sc $0.711 \mu \mathrm{g} / \mathrm{kg}, \quad \mathrm{V} \quad 7.025 \mu \mathrm{g} / \mathrm{kg}, \quad \mathrm{Cr} \quad 78.201 \mu \mathrm{g} / \mathrm{kg}, \quad \mathrm{Mn}$ $1292.577 \mu \mathrm{g} / \mathrm{kg}, \quad \mathrm{Co} \quad 4.941 \mu \mathrm{g} / \mathrm{kg}, \quad \mathrm{Ni} 35.643 \mu \mathrm{g} / \mathrm{kg}, \quad \mathrm{Cu}$ $10240.028 \mu \mathrm{g} / \mathrm{kg}$, As $601.874 \mu \mathrm{g} / \mathrm{kg}$, Sr $242.575 \mu \mathrm{g} / \mathrm{kg}, \mathrm{Ag}$ $1025.272 \mu \mathrm{g} / \mathrm{kg}, \quad$ Cd $0.247 \mu \mathrm{g} / \mathrm{kg}, \quad$ Cs $0.387 \mu \mathrm{g} / \mathrm{kg}, \quad \mathrm{Ba}$ $53.618 \mu \mathrm{g} / \mathrm{kg}, \mathrm{Pb} 10184.186 \mu \mathrm{g} / \mathrm{kg}, \mathrm{Au} 1098.911 \mu \mathrm{g} / \mathrm{kg}$, and $\mathrm{Hg} 5200.500 \mu \mathrm{g} / \mathrm{kg}$. The element content of QSW samples from high to low is $\mathrm{Cu}>\mathrm{Pb}>\mathrm{Hg}$, which are all higher than $5000 \mu \mathrm{g} / \mathrm{kg}$; the contents of Mn, As, Ag, and Au are all higher than $600 \mu \mathrm{g} / \mathrm{kg}$; and the contents of $\mathrm{Li}, \mathrm{Be}, \mathrm{Sc}, \mathrm{V}, \mathrm{Cr}, \mathrm{Co}, \mathrm{Ni}$, $\mathrm{Sr}, \mathrm{Cd}, \mathrm{Cs}$, and $\mathrm{Ba}$ are all less than $300 \mu \mathrm{g} / \mathrm{kg}$.

3.1.3. Content of Minerals and Heavy Metals in QSW after Digestion with Simulated GI Juice. The content of each element after GI digestion was determined. The contents of $\mathrm{Mn}, \mathrm{Cu}, \mathrm{Sr}, \mathrm{Pb}, \mathrm{Au}$, and $\mathrm{Hg}$ in gastric juice $(1 \mathrm{~h})$ are significantly higher than those in water, which may be related to the easier dissolution of these trace elements under acidic conditions. The contents of $\mathrm{Cu}, \mathrm{Au}, \mathrm{Sr}$, and As were higher in intestinal juice $(4 \mathrm{~h})$ than in water. In the simulated digestion experiment of artificial gastric juice and intestinal juice, the release changes of $\mathrm{Cu}$ and $\mathrm{Pb}$ are obvious: in gastric juice, the release of $\mathrm{Cu}$ and $\mathrm{Pb}$ was 17.65 and $30.56 \mu \mathrm{g} / \mathrm{kg}$, respectively; 
while in intestinal juice, the release of $\mathrm{Cu}$ and $\mathrm{Pb}$ was 4.406 and $0.764 \mu \mathrm{g} / \mathrm{kg}$, respectively, and the change of $\mathrm{Pb}$ is the most significant. Therefore, after the clinically used QSW are digested by artificial GI juice, the released heavy metal elements were very low and many elements have fallen below the detection limit. See Table 1 for details.

\subsection{In Vivo Analysis of Minerals and Heavy Metals in QSW by ICP-MS}

3.2.1. In Vivo Processes of Minerals and Heavy Metals. As with previous experiments [20], the model was successful. Table 2 shows that the absorption of Li into the blood is not obvious, which is mainly excreted through feces and urine, and almost no excretion through hair; there is a certain distribution in the brain, suggesting that it may have a certain relationship with the efficacy or toxicity of QSW. The absorption of Be into the blood is not obvious, and the Be absorbed into blood is almost not excreted through urine and hair, and feces are the main excretion route. The absorption of Sc into the blood is not obvious, and the Sc absorbed into the blood is almost not excreted through urine and hair, and feces are its main excretion route. $\mathrm{V}$ is obviously absorbed into the blood, which is mainly excreted through feces and urine but hardly through hair. $\mathrm{Cr}$ is absorbed into the blood obviously; the $\mathrm{Cr}$ absorbed into the blood is hardly excreted through urine and hair, mainly through feces; it is mainly distributed in the brain, suggesting that it may have a certain relationship with the efficacy or toxicity of QSW. The absorption of Mn into the blood is not obvious, and the Mn absorbed into the blood is almost not excreted through urine and hair but mainly through feces; it is mainly distributed in the liver. Co is absorbed into the blood obviously, the Co absorbed into the blood is hardly excreted through urine and hair, and feces are its main excretion route. $\mathrm{Ni}$ is absorbed into the blood obviously, the $\mathrm{Ni}$ absorbed into the blood is hardly excreted through urine and hair, and feces are its main excretion route. The absorption of $\mathrm{Cu}$ into the blood is not obvious, and the $\mathrm{Cu}$ absorbed into the blood is hardly excreted through urine and hair, and feces are its main excretion route. The absorption of As into the blood is not obvious, and the As absorbed into the blood is finally excreted through feces and urine, of which feces are the main route, and it is almost not excreted through hair. Sr is absorbed into the blood obviously, the more it is absorbed over time; the $\mathrm{Sr}$ absorbed into the blood is finally excreted through feces and urine, of which feces is the main route, and it is hardly excreted through hair. Ag is not obviously absorbed into the blood, mainly excreted through feces and urine but almost not through hair; there is a distribution in the kidney at $24 \mathrm{~h}$; there is no obvious distribution in the brain. The absorption of Cd into the blood is not obvious, and it is mainly excreted through feces and urine, but almost not through hair; it is mainly distributed in the brain, suggesting that it may have a certain relationship with efficacy or toxicity of QSW. The absorption of Cs into the blood is not obvious, and it is mainly excreted through feces and urine, but almost not through hair; it is mainly distributed in the kidney. Ba is not obviously absorbed into the blood, and it is mainly excreted through feces, but almost not through urine and hair; it has no obvious distribution in the brain, liver, and kidney. The absorption of $\mathrm{Pb}$ into the blood is obvious, the $\mathrm{Pb}$ absorbed into the blood is finally excreted through feces and urine, of which feces are the main route, and it is almost not excreted through hair; it is mainly distributed in the liver and kidney. The absorption of $\mathrm{Au}$ into the blood is not obvious, and the $\mathrm{Au}$ absorbed into the blood is hardly excreted through urine and hair, and feces are its main excretion route. The absorption of $\mathrm{Hg}$ into the blood is not obvious, and the $\mathrm{Hg}$ absorbed into the blood is excreted through feces, urine, and hair, of which feces is the main path.

\subsubsection{Analysis of the Content of Minerals and Heavy Metals} in Blood and Different Tissues. Changes in the content of minerals and heavy metals in the blood are shown in Table 2 and Figure 1. In hepatic venous blood, the $\mathrm{V}$ content in the QSW + MCAO was significantly reduced compared with the Sham group $(p<0.05)$. In abdominal aortic blood, the contents of V, Cr, Co, Ni, and Sr were increased by QSW + MCAO $(p<0.05)$. However, as far as the content of each trace element in Table 2 is concerned, the trace element content between the Sham and QSW + MCAO groups is not different and the content is extremely low. Taking into account the trace elements in the blood itself, the differences between experimental animals, and the measurement sensitivity of ICP-MS itself, it can be considered that the content of trace elements and even heavy metals in the QSW + MCAO remained in the blood $24 \mathrm{~h}$ after successful modeling is extremely low.

The brain, kidney, and liver were used to analyze the distribution and accumulation of minerals and heavy metals in the tissues, and the results are shown in Table 2 and Figure 2. In brain tissues, the content of $\mathrm{Li}$ increased by QSW + MCAO $(p<0.05)$, while the content of Cr and Cd decreased significantly $(p<0.05)$. In kidney tissues, $\mathrm{Ag}$ and Cs contents increased by QSW + MCAO at $24 \mathrm{~h}$ of MCAO $(p<0.05)$. In liver tissues, the content of $\mathrm{Mn}$ increased by QSW + MCAO at $24 \mathrm{~h}$ of MCAO, while the content of Ni decreased $(p<0.05)$. The results showed that at $24 \mathrm{~h}$ of QSW + MCAO, the content of Mn in the liver was higher than that of the Sham group and was statistically significant (Table 2). Therefore, we speculate that the liver of $\mathrm{QSW}+\mathrm{MCAO}$ rats is the site of Mn metabolism.

Urine, hair, and feces are main excretion routes for minerals, and the results are shown in Table 2 and Figure 3. In urine, at $24 \mathrm{~h}$ of QSW + MCAO, the contents of $\mathrm{Li}, \mathrm{V}, \mathrm{Sr}, \mathrm{Ag}$, $\mathrm{Cd}, \mathrm{Cs}$, and $\mathrm{Hg}$ increased significantly $(p<0.05)$. In the hair, the content of Ni decreased, while the content of $\mathrm{Hg}$ increased by QSW + MCAO $(p<0.05)$. In feces, at $24 \mathrm{~h}$ of MCAO, the contents of $\mathrm{Li}, \mathrm{V}, \mathrm{Cr}, \mathrm{Mn}, \mathrm{Co}, \mathrm{Cu}, \mathrm{As}, \mathrm{Sr}, \mathrm{Ag}, \mathrm{Cd}, \mathrm{Cs}, \mathrm{Ba}, \mathrm{Pb}$, and $\mathrm{Hg}$ increased significantly $(p<0.05)$. Therefore, we speculate that the hair of QSW + MCAO rats could be the site of $\mathrm{Hg}$ metabolism. Although other elements are not statistically significant, their content is still increasing sharply (Be, $\mathrm{Sc}, \mathrm{Ni}, \mathrm{Au}$ ). It can be seen that feces is the main excretion pathway of trace elements and heavy metals in QSW. 
TABLE 1: Determination results of contents of 18 elements in GI juice $(\mu \mathrm{g} / \mathrm{kg})$.

\begin{tabular}{|c|c|c|c|c|}
\hline Element & $\begin{array}{c}\text { Water extraction } \\
(1 \mathrm{~h}) /(\mu \mathrm{g} / \mathrm{kg})\end{array}$ & Stomach digestion $(1 \mathrm{~h}) /(\mu \mathrm{g} / \mathrm{kg})$ & Water extraction $(4 \mathrm{~h}) /(\mu \mathrm{g} / \mathrm{kg})$ & Intestinal digestion $(4 \mathrm{~h}) /(\mu \mathrm{g} / \mathrm{kg})$ \\
\hline $\mathbf{L i}$ & 0.044 & - & 0.094 & 0.049 \\
\hline Be & - & - & - & - \\
\hline Sc & - & - & - & - \\
\hline $\mathbf{V}$ & - & - & - & - \\
\hline $\mathrm{Cr}$ & - & - & - & - \\
\hline Mn & 0.518 & 6.179 & - & - \\
\hline Co & 0.040 & 0.081 & 0.011 & 0.019 \\
\hline $\mathrm{Ni}$ & 2.653 & - & - & - \\
\hline $\mathrm{Cu}$ & 2.292 & 17.651 & 0.853 & 4.406 \\
\hline As & 3.663 & 4.228 & 0.581 & 0.845 \\
\hline Sr & 0.446 & 8.598 & 0.080 & 0.928 \\
\hline Ag & 72.985 & 51.974 & 45.854 & 41.845 \\
\hline Cd & - & - & - & - \\
\hline Cs & 0.004 & 0.013 & - & 0.006 \\
\hline $\mathbf{B a}$ & - & - & - & - \\
\hline $\mathbf{P b}$ & 1.686 & 30.558 & 1.269 & 0.764 \\
\hline Au & 1.790 & 4.846 & 0.903 & 2.959 \\
\hline $\mathrm{Hg}$ & 1.170 & 4.518 & 3.406 & 1.102 \\
\hline
\end{tabular}

The symbol "-" means not detected or lower than the detection limit. Bold indicates that the data are consistent with other data.

Compared with the content of minerals and heavy metals in QSW itself, it can be seen that the content of 18 elements in the abdominal aortic blood, hepatic venous blood, brain, liver, and kidney of QSW + MCAO rats is extremely low, the absorption is not high, and most of them are excreted through feces, and a few are excreted through urine and hair, which further proves taking QSW is relatively safe.

\section{Discussion}

This study concludes that the contents of $\mathrm{Hg}, \mathrm{Cu}, \mathrm{Pb}, \mathrm{Ag}, \mathrm{As}$, $\mathrm{Mn}$, and $\mathrm{Au}$ in QSW are relatively high. Under normal conditions, intake of such high levels of trace elements and even heavy metals is toxic to the human body when in excess amounts. However, after QSW were digested by artificial GI juice, the release of these heavy metals is very low, and many elements have fallen below the detection limit. These minerals and heavy metals must also be absorbed into the blood to exert their physiological effects in the human body. Hence, the low release of heavy metals may be acceptable. Finally, one QSW pill usually takes 3 to 7 days to be absorbed. At this time, the body's normal metabolism will also metabolize most of the trace elements. Therefore, the high content of trace elements and even heavy metals in QSW is not a sound basis to declare this Tibetan medicine as unsafe. The Pharmacopoeia of the People's Republic of China only conducts the microscopic identification of pearl, nine eye stone, and Dalbergia odoratum and the thin-layer identification of cholic acid, saffron, agarwood, benzoin, and safflower [4]. This process does not involve the quality control of trace elements or even heavy metals. However, heavy metals should have strict limits whether they are being used as toxic ingredients or as the basis of medicinal substances. At present, the research on minerals and heavy metals in QSW at home and abroad is still in infancy. No work has focused on the in vivo and in vitro aspects to systematically and quantitatively analyze the content of minerals and heavy metals in QSW. According to the in vitro simulated gastric digestion experiment in this work, the dissolution rate of other elements is higher than that of water extraction, except for the undetected and Ag elements. Two explanations for this phenomenon are presented. One is that hydrochloric acid destroys the internal structure of these minerals and heavy metals, thus allowing them to be dissolved in gastric juice. Another is the precipitation reaction of free silver dissolved in gastric juice and hydrochloric acid, thereby lowering the total silver content in gastric juice compared with that in water. In the simulated intestinal digestion experiment, the content of almost all detected minerals and heavy metals was far lower than that in the gastric juice.

Zuotai, an important component in QSW, is mainly made of mercury. It is not used alone in clinical practice but plays an important role in Tibetan medicine preparations, such as improving curative effects, reducing side effects, strengthening the spleen, and nourishing the body. [31]. Because Zuotai contains mercury, which is a toxic heavy metal element, its safety has received extensive attention. Previous studies [32] have conducted experiments on the dissolution of Zuotai in simulated GI, and the results showed that the dissolution of mercury in the simulated intestinal juice of Zuotai was significantly lower than that in the simulated gastric juice. Our study on QSW also showed the same result. Therefore, gastric juice digestion plays a key role in the absorption and metabolism of minerals and heavy metals in QSW.

The content of minerals and heavy metals in cerebral ischemia rats treated with QSW was determined. In our experiment, we also studied the QSW with a dose of $5 \mathrm{~g} / \mathrm{kg}$ and executed them at $0.5 \mathrm{~h}$ after making the model. The results showed that there was no significant difference from the Sham group. The reason may be that the time is too 


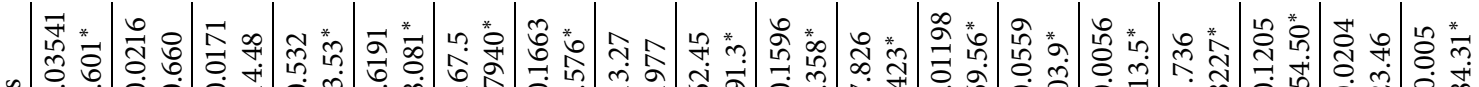

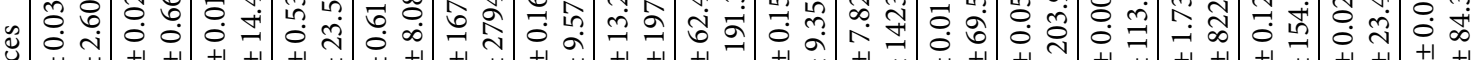

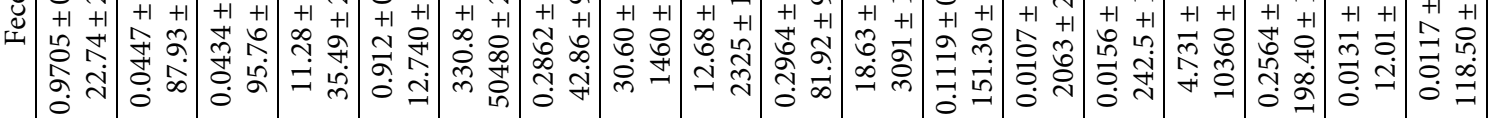

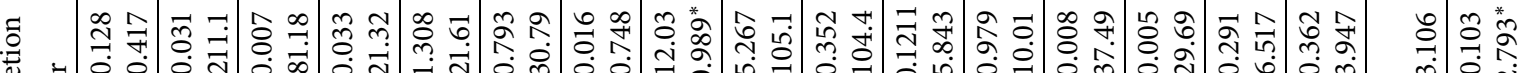

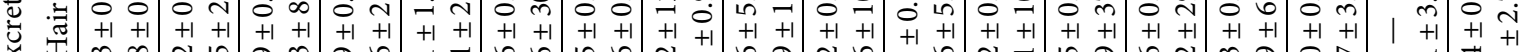

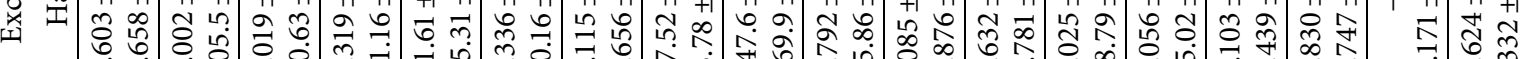

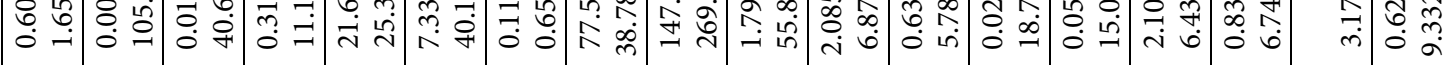

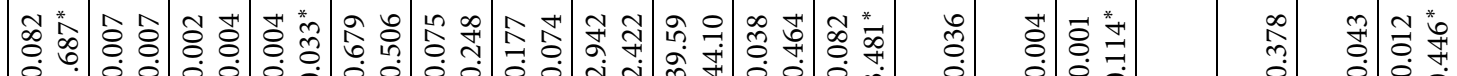

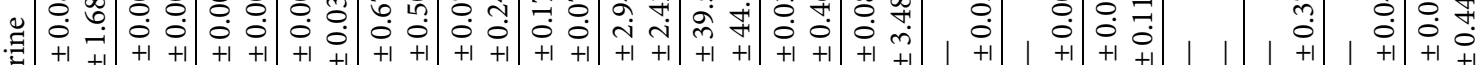

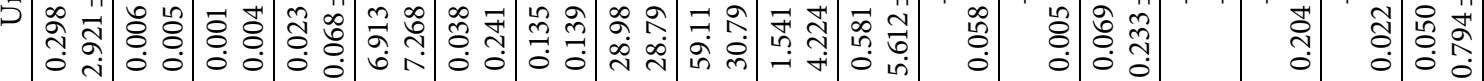

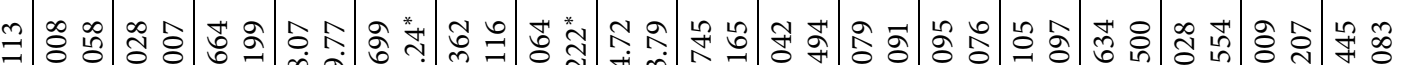

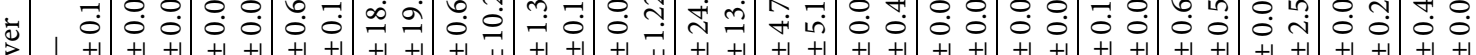
J

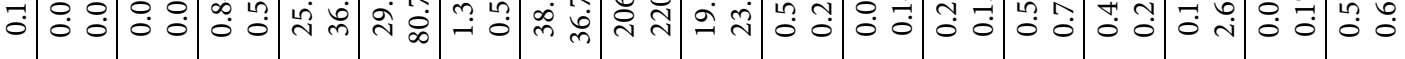

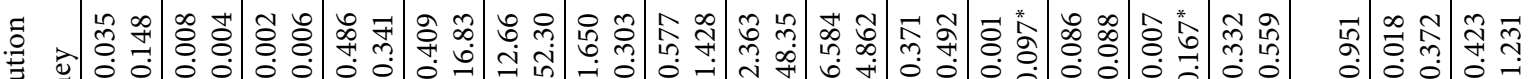

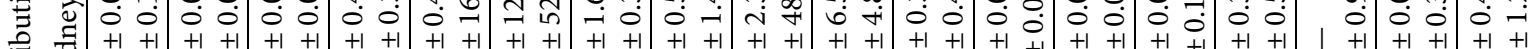

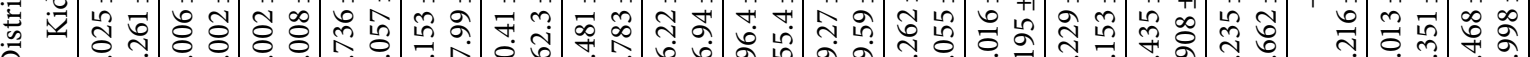

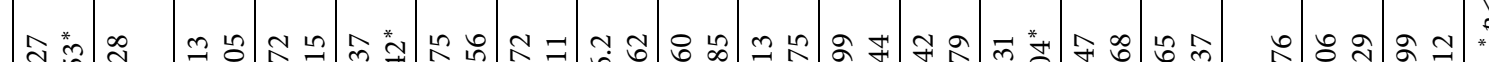

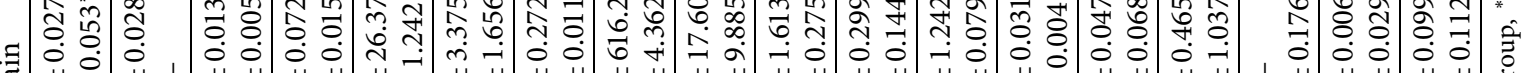

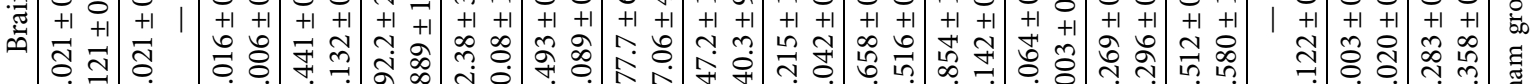

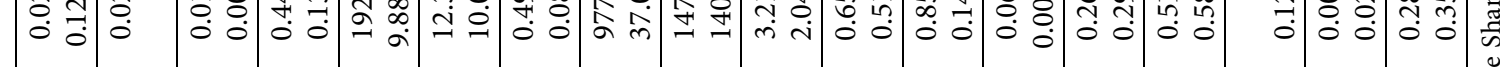

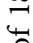

苞

$\overline{0}$

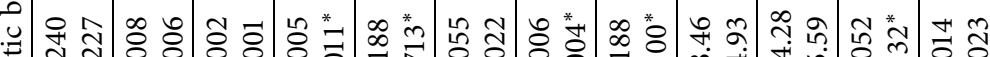

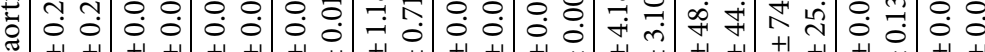

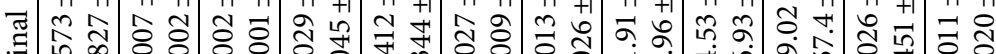

ही

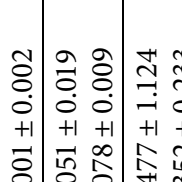

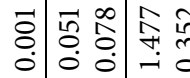
告

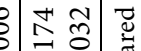

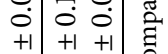

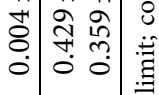
䓀,

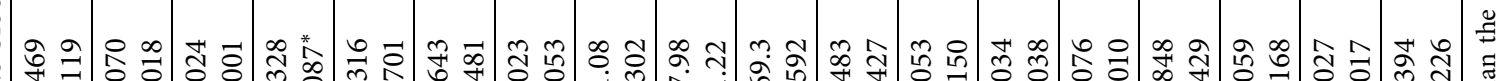

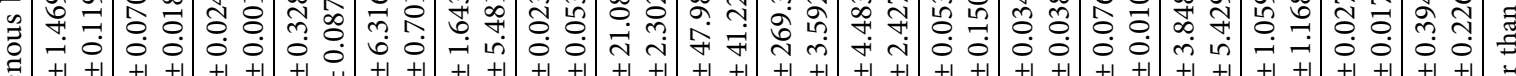

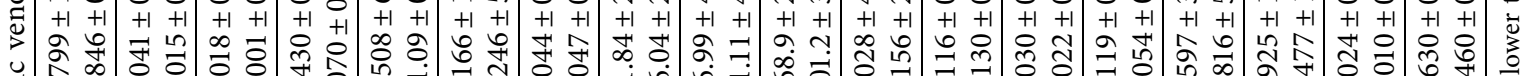
言

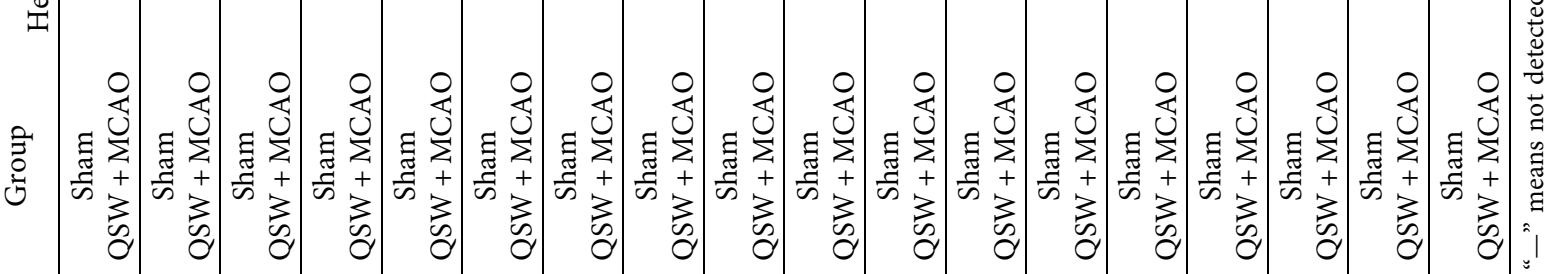

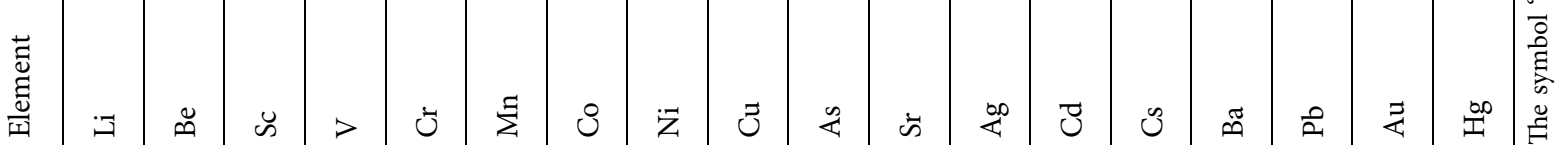



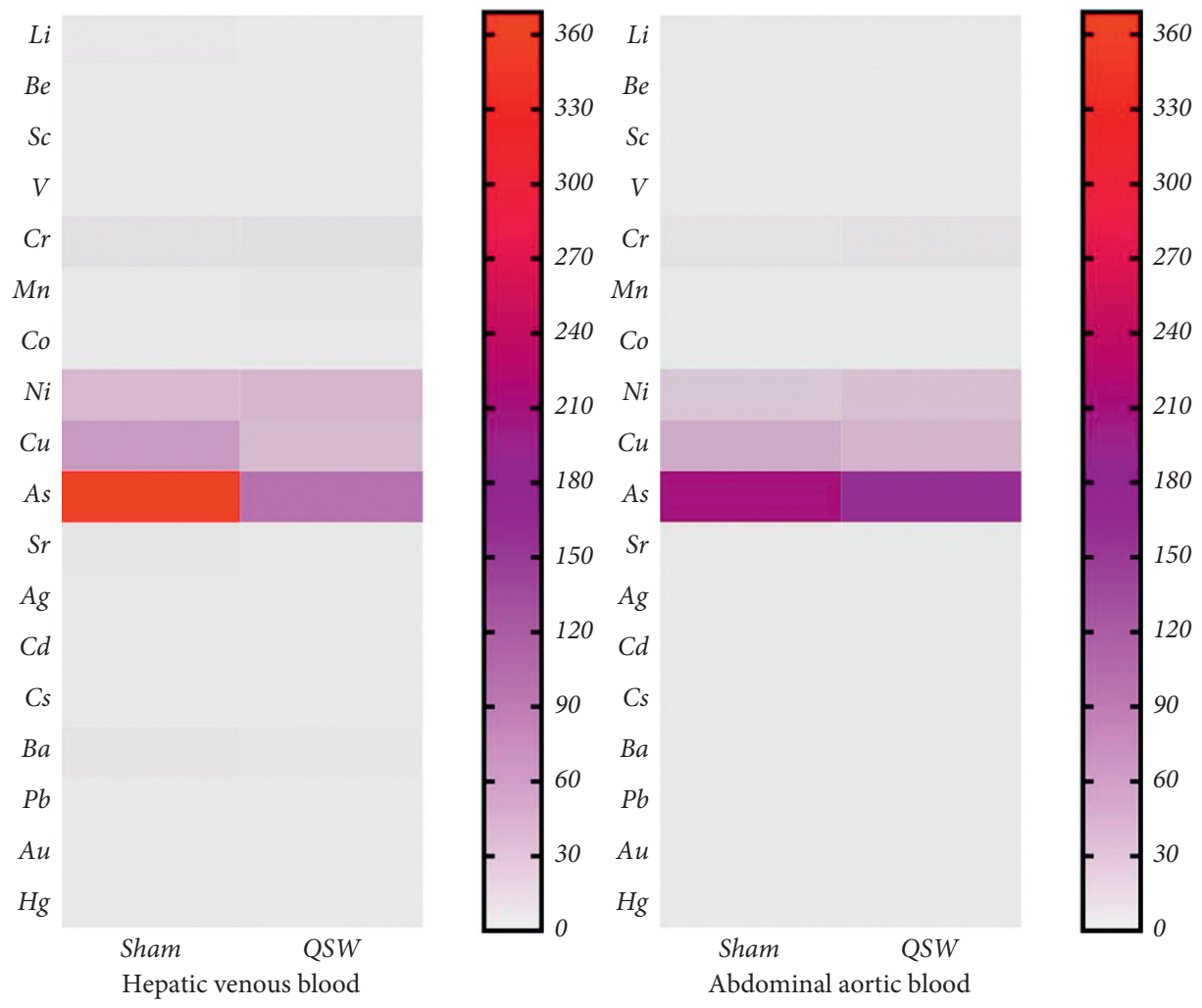

Figure 1: Heatmap of 18 elements in the artery and vein $(n=6)$. (Note. The redder the color, the higher the content; the grayer the color, the lower the content.)
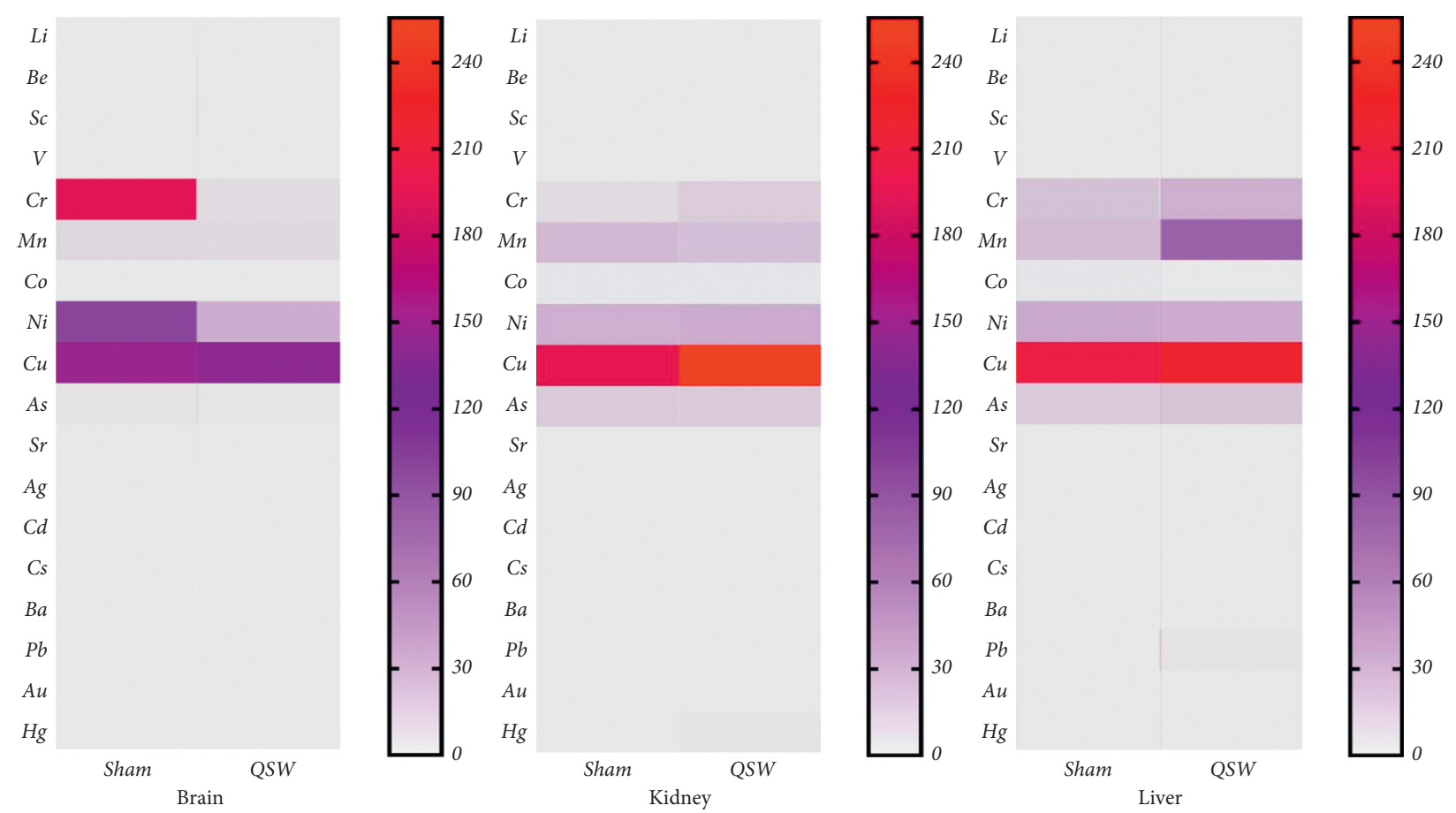

Figure 2: Heatmap of 18 elements in the brain, kidney, and liver $(n=6)$. (Note. The redder the color, the higher the content; the grayer the color, the lower the content.) 

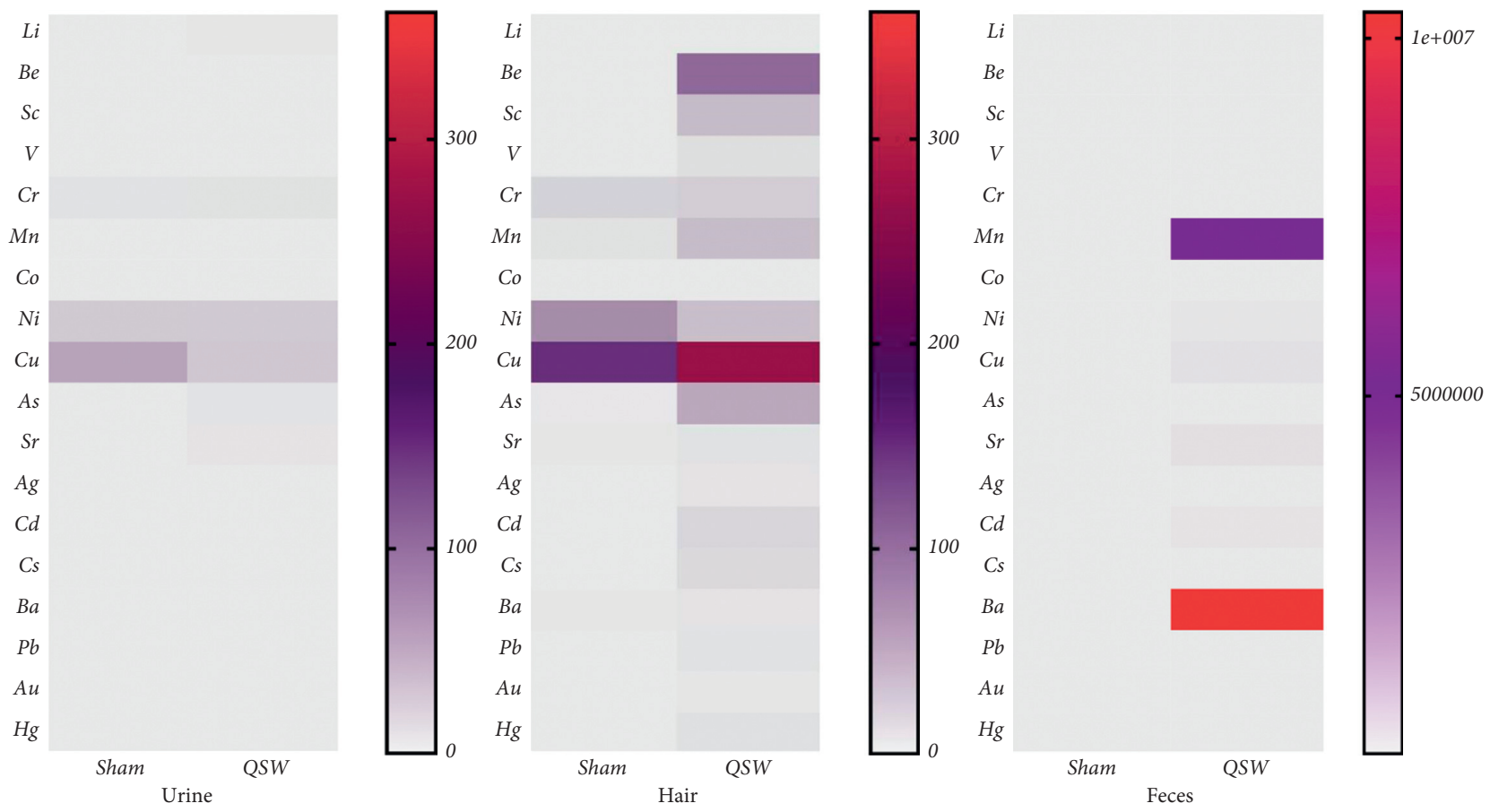

Figure 3: Heatmap of 18 elements in urine, hair, and feces $(n=6)$. (Note. The redder the color, the higher the content; the grayer the color, the lower the content.)

short; the elements of QSW cannot be absorbed and distributed, even if its dose is large enough. These pilot results showed that it takes a certain period of time to produce effect after taking QSW.

When the rats were treated with QSW $(66.68 \mathrm{mg} / \mathrm{kg})$ first, then at $24 \mathrm{~h}$ of successful modeling, the $\mathrm{Hg}, \mathrm{Pb}, \mathrm{Cu}, \mathrm{As}$, and other heavy metal elements are mainly excreted in feces, and the heavy metals that are absorbed into the blood or accumulated in the brain, liver, kidney, and other tissues are extremely low. Nonetheless, in the measurement of elements accumulated in brain tissues, it was found that the content of $\mathrm{Li}$ increased, and the content of $\mathrm{Cd}$ and $\mathrm{Cr}$ decreased, and both were significant; Li was absorbed into the body and mainly distributed in the brain, indicating that its main target site to exert its pharmacological or toxic effects is the brain. Hence, $\mathrm{Li}$ is possibly to be the material basis of QSW for the treatment of cerebral ischemia. According to reports in the literature, Li can improve the integrity of the bloodbrain barrier, sensorimotor deficits, and cerebral edema in animals with cerebral hemorrhage [33]. The excretion of minerals in the feces is the main route of disposition of these elements, including the above three. Considering their longterm stay in the GI tract, the gut-microbiota-brain axis in QSW-mediated brain protection is evident [21].

QSW is rich in minerals and heavy metals than other Chinese patent medicines. These toxic elements cause strong toxic reactions only when in their free form and in excess; if minerals and heavy metals are combined with other macromolecular compounds, then their toxic reactions are greatly weakened or directly converted into nontoxic chemical compounds [34]. Heavy metals are generally viewed as toxic to the human body. From the perspective of traditional medicine, toxicity can be reduced by processing or strict dosage control; "both poison and medicine" is a relevant saying. Main ingredients, such as Zuotai of QSW, must undergo "mercury refining method" [35] to ensure that the toxicity of $\mathrm{Hg}$ and other metal elements is greatly reduced or even removed. When metals enter the body, complex physiological changes may cause them to combine with certain macromolecular substances to reduce their toxicity or exert pharmacological effects. For example, when $\mathrm{Cd}$ and $\mathrm{Cr}$ are absorbed into the blood and are distributed in the brain, they may combine with some macromolecular substances to exhibit a therapeutic effect. Whether decreased $\mathrm{Cd}$ and $\mathrm{Cr}$ in the brain by QSW could contribute to its neuroprotection is unknown and worth investigating. QSW increased $\mathrm{Ag}$ and $\mathrm{Cs}$ in the kidney and increased Mn but decreased $\mathrm{Ni}$ in the liver; the biological significance of such changes also requires further investigation. In addition, the human body's absorption of mercury and other minerals is low mainly because most of them are excreted in feces, which indicates the importance of the gut-microbiota-brain axis in QSW-mediated brain protection; secondly, the content of trace elements of the human body required is not high, although the absorption is low, it may just meet the needs of the human body. Moreover, the $\mathrm{Li}, \mathrm{Cr}, \mathrm{Cd}$, and other elements detected in brain tissues are likely to be the material basis for QSW to treat cerebral ischemia.

However, what about the accumulation of QSW in the body after long-term use? The dosage of QSW in the instructions is $1 \mathrm{~g}$ ( 1 pill) per day for critically ill patients, and general patients take $1 \mathrm{~g}$ every 3 to 7 days. In this study, rats were given the clinically equivalent dose of QSW, that is, the optimal dose $(66.68 \mathrm{mg} / \mathrm{kg})$, and within $24 \mathrm{~h}$ after the 
successful modeling, most of the minerals and heavy metals have been excreted through urine or feces, and then after 3 to 7 days, the minerals and heavy metals in the body may be less. Therefore, whether it is for critically ill patients or general patients, the accumulation of minerals and heavy metals in the body after long-term use of QSW is very small and basically does not accumulate; it is safe to take QSW.

In our experiment, the results showed that these elements can be detected in the Sham group. These trace elements could be essential components in the body. This study is the first to use ICP-MS to examine the in vivo absorption, distribution, and excretion of minerals and heavy metals from QSW and further objectively prove its safety. However, there is also one deficiency, that is, we did not set up the model control group (MCAO group), and we do not know whether it will affect the content of these elements in the body after modeling. Nonetheless, Sham rats without receiving QSW provided a basal control for absorption, distribution, and excretion of elements following QSW administration.

\section{Conclusions}

Quantifying the minerals and heavy metals in QSW in vivo and in vitro will help improve its quality standards. The abundant minerals and heavy metals in this medicine may either be the basis of its main medicinal substances or promote the therapeutic effects of its effective ingredients. The absorption, distribution, and excretion of minerals and heavy metals from QSW in MCAO rats add to our understanding of neuroprotective effects of QSW. The accumulation of the elements in blood and tissues was extremely low, and the majority was excreted in feces within $24 \mathrm{~h}$, highlighting the importance of the gut-microbiota-brain axis in QSW-mediated brain protection.

$\begin{array}{ll}\text { Abbreviations } \\ \text { QSW: } & \text { Qishiwei Zhenzhu pills } \\ \text { ICP-MS: } & \text { Inductively coupled plasma mass spectrometry } \\ \text { GI: } & \text { Gastrointestinal } \\ \text { MCAO: } & \text { Middle cerebral artery occlusion } \\ \text { ICP- } & \text { Inductively coupled plasma-atomic emission } \\ \text { AES: } & \text { spectrometry } \\ \text { SR-XRF: } & \text { Synchrotron radiation X-ray fluorescence } \\ \text { FAAS: } & \text { Flame atomic absorption } \\ \text { GAE- } & \text { Gold amalgam enrichment-atomic fluorescence } \\ \text { AFS: } & \\ \text { ISS: } & \text { Internal standard stock solution } \\ \text { SS: } & \text { Standard solution } \\ \text { PTEF: } & \text { Polytetrafluoroethylene } \\ \text { CCA: } & \text { Common carotid artery } \\ \text { ECA: } & \text { External carotid artery } \\ \text { ICA: } & \text { Internal carotid artery. }\end{array}$

\section{Data Availability}

Data supporting the conclusions are included in the manuscript. The data sets used and/or analyzed during the current study are also available from the corresponding author on reasonable request.

\section{Ethical Approval}

The use of animals was approved by the Sichuan Provincial Committee for the Control of Experimental Animals, Chengdu University of Traditional Chinese Medicine, and conformed to the Guide for the Care and Use of Laboratory (approval number: SYXK (Chuan) 2020-124).

\section{Conflicts of Interest}

All authors declare no conflicts of interest.

\section{Authors' Contributions}

Yinglian Song, Ke Fu, and Dewei Zhang contributed equally to this work. Yinglian Song and $\mathrm{Ke}$ Fu are responsible for assisting in the experiment and participating in the writing of articles; Dewei Zhang is mainly responsible for the research; Min Xu, Ruixia Wu, Xueqing Xiong, Xianwu Liu, Lei $\mathrm{Wu}$, Ya Guo, You Zhou, and Xiaoli Li are responsible for assisting in the experiment.

\section{Acknowledgments}

This study was supported by China Postdoctoral Science Foundation (2012M511916); the Project of Sichuan Provincial Administration of Traditional Chinese Medicine (2012-E-040); and the Science and Technology Development Fund of Chengdu University of Traditional Chinese Medicine (ZRQN1544). The authors thank the Chengdu University of Traditional Chinese Medicine and Wenzhou Institute for Drug and Food Control for providing with a research platform in this article; and Zhang Wang directs the writing of the article and functions as our corresponding author.

\section{Supplementary Materials}

Supplementary Table 1. Composition of QSW. Supplementary Table 2. Results of linear equations and correlation coefficients of 18 elements. (Supplementary Materials)

\section{References}

[1] J. Wu, Neurology, pp. 150-192, People's Medical Publishing House, Beijing, China, 2005.

[2] C. J. Liu, Study on the Relationship between Middle Cerebral Artery Stenosis and Progressive Ischemic Stroke, Nangchang University, Nanchang, China, 2019.

[3] L. J. Zheng, X. Q. Ren, M. Q. Wang et al., "Exploring the rule of the diagnosis and treatment of stroke based on the Tibetan medical theory of white meridian," Modernization of Traditional Chinese Medicine and Materia Medica-World Science and Technology, vol. 19, no. 2, pp. 370-374, 2017.

[4] National Pharmacopoeia Committee, Pharmacopoeia of the People's Republic of China. Vol. I, China Medical Science and Technology Press, Beijing, China, 2015. 
[5] W. L. Xu, W. J. Sun, and Z. Wang, "Comparison with the modern research progress of the Rannasangpei and twenty five pearl pill based on prescription data mining," Chinese Journal of Ethnomedicine and Ethnopharmacy, vol. 26, no. 4, pp. 59-63+71, 2017.

[6] E. J. An and Y. R. Suo, "Advances in modern pharmacology of Qishiwei Zhenzhu pills of Tibetan medicine," Journal of Medicine \& Pharmacy of Chinese Minorities, vol. 10, no. 2, pp. 33-35, 2004.

[7] L.-L. Zhou, H.-J. Chen, Q.-Q. He, C. Li, L.-X. Wei, and J. Shang, "Evaluation of hepatotoxicity potential of a potent traditional Tibetan medicine Zuotai," Journal of Ethnopharmacology, vol. 234, pp. 112-118, 2019.

[8] C. Li, W. Xu, S. Chu et al., "The chemical speciation, spatial distribution and toxicity of mercury from Tibetan medicine Zuotai, $\beta$-HgS and $\mathrm{HgCl} 2$ in mouse kidney," Journal of Trace Elements in Medicine \& Biology, vol. 45, pp. 104-113, 2018.

[9] Q. Wu, W.-K. Li, Z.-P. Zhou et al., “The Tibetan medicine Zuotai differs from $\mathrm{HgCl} 2$ and $\mathrm{MeHg}$ in producing liver injury in mice," Regulatory Toxicology and Pharmacology, vol. 78, pp. 1-7, 2016.

[10] H. X. Yang, C. Li, Y. Z. Du, and L.-X. Wei, "Metallic elemental analysis of Tibetan herbal medicines and Tibetan medicine preparations by synchrotron radiation X-ray fluorescence," Spectroscopy and Spectral Analysis, vol. 35, no. 6, pp. 17301734, 2015.

[11] J. F. Jiang, L. X. Wei, and Y. Z. Du, "Determination of calcium and other five trace elements in calcium from four provinces by FAAS with wet digestion," Chinese Journal of Spectroscopy Laboratory, vol. 28, no. 6, pp. 2862-2865, 2011.

[12] C. Li, H. X. Yang, and L. X. Wei, "Determination of total mercury and ionic mercury in artificial gastric juice of Tibetan medicine Dangzuo by GAE-AFS," Spectroscopy and Spectral Analysis, vol. 31, no. 7, pp. 1950-1953, 2011.

[13] D. Y. Chen and T. Christopher, "ICP-MS and its application," Modern Instruments \& Medical Treatment, no. 4, pp. 8-11+38, 2001.

[14] J. Q. Huang, X. Hu, and J. R. Zhang, "Application of ICP-MS technology in pharmaceutical analysis," China Pharmacy, vol. 17, no. 8, pp. 624-626, 2006.

[15] L.-Y. Du, T. Jiang, K. Wei et al., "Simultaneous quantification of four ginsenosides in rat plasma and its application to a comparative pharmacokinetic study in normal and depression rats using UHPLC-MS/MS," Journal of Analytical Methods in Chemistry, vol. 2021, Article ID 4488822, 11 pages, 2021.

[16] Y. R. Suo, T. C. Li, and C. Q. Ai, "Study on mineral elements of Tibetan medicine Qishiwei zhenzhu pills," Qinghai Science and Technology, vol. 10, no. 5, pp. 26-29, 2003.

[17] Y. Li, F. S. Yi, and T. C. Li, "Determination of trace elements in Tibetan medicine Qishiwei zhenzhu pills," Guangdong Trace Elements Science, vol. 8, no. 11, pp. 51-52, 2001.

[18] T. C. Li and Y. R. Suo, "Study on the accumulation level of mineral elements in Tibetan medicine Qishiwei zhenzhu pills," Journal of the Graduate School of the Chinese Academy of Sciences, vol. 20, no. 3, pp. 348-352, 2003.

[19] Z. Du, B. Z. Ciren, and B. Gong, "Distribution and excretion of toxic heavy metals in Qishiwei zhenzhu pills in beagle dogs," Pharmaceutical Journal of Chinese People's Liberation Army, vol. 27, no. 6, pp. 487-489, 2011.

[20] M. Xu, R. X. Wu, Y. Liang et al., "Protective effect and mechanism of Qishiwei Zhenzhu pills on cerebral ischemiareperfusion injury via blood-brain barrier and metabonomics," Biomedicine \& Pharmacotherapy, vol. 131, 2020.
[21] K. Fu, D. W. Zhang, Y. L. Song et al., "Tibetan medicine Qishiwei Zhenzhu pills can reduce cerebral ischemia-reperfusion injury by regulating gut microbiota and inhibiting inflammation," Evidence-Based Complementary and Alternative Medicine, vol. 2021, Article ID 2251679, 13 pages, 2021.

[22] National Pharmacopoeia Committee, Pharmacopoeia of the People's Republic of China. Vol. IV, Vol. 130, China Medical Science and Technology Press, ,Beijing,China, 2015.

[23] P. Jin, X. Liang, L. Xia et al., "Determination of 20 trace elements and arsenic species for a realgar-containing traditional Chinese medicine Niuhuang Jiedu tablets by direct inductively coupled plasma-mass spectrometry and high performance liquid chromatography-inductively coupled plasmamass spectrometry," Journal of Trace Elements in Medicine \& Biology, vol. 33, pp. 73-80, 2016.

[24] W. W. Liang, C. J. Huang, and Z. Wang, "Preliminary study of time-effect relationship of Tibetan Rannasangpei Pills for the treatment of cerebral ischemia-reperfusion injury," Pharmacology and Clinics of Chinese Materia Medica, vol. 31, no. 1, pp. 182-187, 2015.

[25] W. L. Xu, W. J. Sun, and Z. Wang, "Dose-effect relationship of Qishiwei Zhenzhu Pills against cerebral ischemicreperfusion injury in rats," Drugs \& Clinic, vol. 32, no. 1, pp. 10-15, 2017.

[26] Y. Liang, Study on the Blood Absorption Components and the Mechanism of Rannasangpei for Blood-Brain Barrier Injury after Cerebral Ischemia Based on GC-MS Metabonomics, Chengdu University of Traditional Chinese Medicine, Chengdu, China, 2019.

[27] G. Liu, G. Tang, W. Liang et al., "PK-PD correlation of Erigeron breviscapus injection in the treatment of cerebral ischemia-reperfusion injury model rats," Journal of Molecular Neuroscience, vol. 71, no. 2, pp. 302-324, 2020.

[28] Y. Liang, K. Fu, and Z. Wang, "Study on the dose-time-effect relationship of Tibetan medicine rannasangpei in cerebral ischemiareperfusion injury model rats with intragastric administration," China Pharmacy, vol. 30, no. 1, pp. 94-98, 2019.

[29] Y. Liang, W. J. Sun, and Z. Wang, "Protective effects of Qishiwei Zhenzhu Pills on blood-brain barrier in cerebral ischemia-reperfusion injury rats," Chinese Traditional Patent Medicine, vol. 41, no. 4, pp. 767-773, 2019.

[30] H. L. Guo, S. Zhang, and L. Y. Liu, "Determination of 13 kinds of metal elements in 10 common Chinese materia medica injections by ICP-MS," Chinese Traditional and Herbal Drugs, vol. 46, no. 17, pp. 2568-2572, 2015.

[31] B. S. Yang, J. C. Jiang, and Y. Jiang, "Study on the features and safety of mercury in the Tibetan medicine "Zuotai"," Tibetan Studies, no. 1, pp. 74-80, 2004.

[32] M. Zhang, H. T. Bi, and C. Li, "The difference of mercury dissolution of Tibetan medicine Zuotai in simulated gastric juice and intestinal juice," Chinese Traditional Patent Medicine, vol. 40, no. 10, pp. 2302-2304, 2018.

[33] W. Li, R. Li, S. Zhao, C. Jiang, Z. Liu, and X. Tang, "Lithium posttreatment alleviates blood-brain barrier injury after intracerebral hemorrhage in rats," Neuroscience, vol. 383, pp. 129-137, 2018.

[34] Y. F. Shi, M. Y. Xie, and S. P. Nie, "Study on elemental speciation analysis and transference characteristics of Arnebia euthroma (Royle) Johnst by ICP-MS," Spectroscopy and Spectral Analysis, vol. 27, no. 2, p. 378, 2007.

[35] M. M. Wang, Y. Z. Lv, and L. Suo, "The current situation and countermeasures of the development of Tibetan medicine with mercury refining method and Tibetan medicine," Journal of Medicine \& Pharmacy of Chinese Minorities, vol. 24, no. 12, pp. 26-28, 2018. 